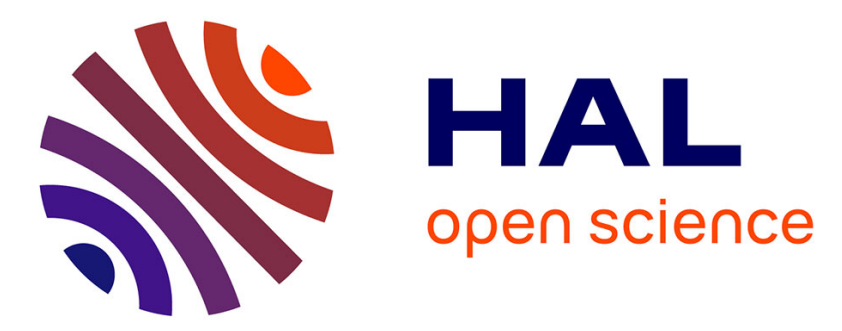

\title{
Integrated Framework to Manage Building's Sustainability Efficiency, Design Features and Building Envelope
}

Tala Kasim, Haijiang Li, Yacine Rezgui, Thomas Beach

\section{- To cite this version:}

Tala Kasim, Haijiang Li, Yacine Rezgui, Thomas Beach. Integrated Framework to Manage Building's Sustainability Efficiency, Design Features and Building Envelope. 19th Working Conference on Virtual Enterprises (PRO-VE), Sep 2018, Cardiff, United Kingdom. pp.650-660, 10.1007/978-3-319-991276_56. hal-02191199

\author{
HAL Id: hal-02191199 \\ https://hal.inria.fr/hal-02191199
}

Submitted on 23 Jul 2019

HAL is a multi-disciplinary open access archive for the deposit and dissemination of scientific research documents, whether they are published or not. The documents may come from teaching and research institutions in France or abroad, or from public or private research centers.
L'archive ouverte pluridisciplinaire HAL, est destinée au dépôt et à la diffusion de documents scientifiques de niveau recherche, publiés ou non, émanant des établissements d'enseignement et de recherche français ou étrangers, des laboratoires publics ou privés.

\section{(c)(1)}

Distributed under a Creative Commons Attribution| 4.0 International License 


\title{
Integrated Framework to Manage Building's Sustainabil- ity Efficiency, Design Features and Building Envelope
}

\author{
Tala Kasim ${ }^{1, *}$, Haijiang $\mathrm{Li}^{2}$, Yacine Rezgui ${ }^{2}$, and Tom Beach ${ }^{2}$ \\ ${ }^{1}$ School of Engineering and Applied Science, Aston University, Birmingham, UK \\ tala.kasim@yahoo.com \\ ${ }^{2}$ School of Engineering, Cardiff University, Cardiff, UK \\ (Lih, rezguiy, beachth)@ cardiff.ac.uk
}

\begin{abstract}
The construction industry is facing a challenge to move towards a more sustainable sector with energy-efficient buildings and sustainable design features. Building design and construction process are conditioned by numerous sustainability regulations and assessment measures. With the increasing use of building simulations, the potential of improving design features and promoting efficient construction has become a routine practice, starting at early stages of design and carried out throughout the life cycle of a building. Nevertheless, the construction process is currently lacking the presence of integrated systems that allow dynamic compliance checking of design features with building regulations using instant results from building simulation tools. Such integrated system requires access to regulatory compliance data and appropriate information exchange mechanism between building information model, regulatory requirements and building simulations tools. This paper will present an initiative for developing an integrated system that facilitates managing building performance dynamically through an appropriate information management process combining sustainability regulatory and building simulations with building information modeling. The paper will present a valid implementation results of compliance checking against some criteria of BREEAM assessment process. The quantitative analysis of the results revealed that more than $50 \%$ of compliance requirements cannot be fully automated and still requires users input. This is due to the fact that the IFC data model used for data extraction lacks a representation of certain domains of data.
\end{abstract}

Keywords: Regulatory compliance checking, Building simulations tools, Building information modeling

\section{$1 \quad$ Introduction}

The construction industry requires immediate and effective solutions to design sustainable and high-performance buildings to meet the needs of the 21 st century (Everett et al., 2012). The use environmental assessment systems to evaluate building per- 
formance has been widely implemented across the world to examine building compliance with sustainability requirements. These tools have been used during the design, construction and operation stages (Singh et al., 2012). However, the use of these tools has been criticized for being tedious and long processes. This is mainly due to the large amounts of data and information that need to be processed in order to undertake the assessment, further to the nature and the number of the performance criteria and their continuous increasing in details and complexity (Jaffe et al., 2005).

Although there are a plethora of environmental assessment methodologies (e.g., BREEAM and LEED) (Trusty, 2000), however, the efforts needed in achieving the desired sustainable performance have often proved too expensive and time-consuming (Kibert, 2008). There is still a gap in the provision of integrated systems that facilitate the assessment process in a simplified way. Hence, the construction industry needs an urgent fundamental cultural change in environmental assessment and compliance checking methodologies that allow lifecycle performance assessment in an integrated way (Lee and George, 2013).

BIM technologies provide an opportunity to facilitate regulatory compliance checking process in an efficient way (Counsell, 2012). The main characteristic of $\mathrm{BIM}$ is providing a digital representation of building information as a product of the modeling process. This information could be utilized in a smart way in order to undertake efficient processes, and regulatory compliance checking could be one of these processes (Jung and Joo, 2011).

This paper presents an initiative of developing an integrated system that facilitates managing building performance dynamically through appropriate information management process by combining sustainability regulatory and building simulations with building information modeling. The availability of such will have significant advantages of promoting a more efficient regulatory compliance checking process

\section{Background}

Many researchers and software vendors such as Autodesk have reported that BIM tools promote efficient sustainable construction through the availability of building information for compliance checking and simulation (Azhar et al., 2009). By using $\mathrm{BIM}$ as a design tool, an optimized design which meets regulatory requirements of sustainable construction could be achieved. This could be done when designers have access to a comprehensive set of information and knowledge in order to undertake compliance checking, such as building form, location, building components, materials and manufacturer information in addition to relevant technical systems. Since the use of BIM has only been mandated recently, research in the area of developing BIM integrated solutions has been growing. Hence, many researchers have been studying the integration between BIM and sustainability tools (Biswas and Tsung-Hsien Wang, 2008). The aim of these research is to develop an automated assessment process Furthermore, there have been many practical attempts to consider sustainability assessment process as part of building design such as Bentley System's AECOsim Compli- 
ance Manager; "a project management and collaboration service to automate the LEED certification process for the United States Green Building Council's (USGBC)"(Bentley, 2016).

There is a massive amount of sustainability analysis software tools. These tools are used to provide real-time indicators of building performance in line with sustainable construction agenda. Some of these tools are directly linked with environmental assessment methods, for example, IES $\langle\mathrm{VE}>$ for energy analysis has the features of checking compliance against part $\mathrm{L}$ of the English building regulations. IES $<\mathrm{VE}>$ also works parallel with LEED rating system. However, the process still lacks effective interoperability between BIM, regulatory requirements and building simulations tools (Crawley et al., 2001).

The integration between software tools requires an effective mechanism of information exchange. Currently, even within the BIM environment, different software use different data exchange format, as a result, direct integration is difficult to achieve. The most popular data exchange formats are Industry Foundation Classes (IFC) and gbXML and they both have their limitations; IFC does not include all of the information needed for sustainability compliance checking and gbXML is not comprehensive and it lacks lifecycle consideration and

With the increasing use of BIM, several tools have emerged for compliance checking and clash detection. One of the most popular tools is Solibri Model Checker (SMC). "Solibri has been designed to achieve continuous quality control for the building model during its life cycle. Its functionality is based on an information take-off (ITO) capability, which allows users to collect information from the BIM, organize it, visualize it, read the IFC file, map it to its rules structure, and report results instantly. The information that can be checked with SMC includes areas and spatial calculations, the envelope of the building to be used for energy calculations, volumes, and quantities" (Kasim, 2016). Many other systems also exist for design rule checking of examples; EDM Model Checker, and E-plan Check of the Singaporean CORNETE project Jotne Express Data Manager (Eastman et al., 2009)

All the previously reported compliance checking approaches used IFC models to facilitate information exchanging and processing, however, they are not using the full potential of the available information for automated comprehensive compliance (Salama and El-Gohary, 2011). They only focused general features of building design within the architectural and structural design domain. These systems utilize a relatively simple form of rules of building geometry and special attributes to examine compliance checking (Khemlani, 2002). For example, these tools proved efficient in checking access dimensions, wall thickness, doors sizes, and so on (Yang and $\mathrm{Xu}$, 2004). It can be concluded from literature review findings that BIM integrated solutions for sustainability checking is still in its early stages (T Kasim, 2013). Therefore, this paper presents the methodology that has been developed for a more comprehensive assessment process. The methodology presented in this paper aim at promoting an efficient integrated system for compliance checking which could be used iteratively to simulate the performance criteria against targeted regulations dynamically throughout the life cycle of building design and construction. This will facilitate compliance checking process as the design develops and building operates. In addition to 
providing designer with constant feedback on methods for optimized design with a desired building performance.

\subsection{Regulatory Compliance}

The field of sustainable engineering is facing the phenomena of increased numbers of regulations, building codes, and best practices. Furthermore, these regulations are growing massively in their volumes and complexity to meet the requirements of efficient designs, sustainable construction while reducing carbon footprints. Building codes and regulations cover a diverse range of aspects, falls under different categories with the aim of meeting the optimum functional requirements of building design while maintaining the environment. Hence, the categories of sustainable design regulations range from rules for promoting efficiency through energy and water consumptions, rules for sustainable logistics and supply chain management and rules for environmental protection through the choice of sustainable construction materials. There are significant differences between the global and national diverse building regulations, mainly in terms of their originality, historical development and the various emphasis on environmental issues. Nevertheless, the majority of these regulations share similar purposes and uses almost the same compliance checking methods and procedures.

The nature of these regulations can be described as either feature-based exigency or ward performance-based requirements; for instance, the assessment of energy efficiency is determined from both building design features such as (the choice of building materials, isolations, fittings and other specifications) the performance according to energy utilities.

The traditional methods by which compliance requirements are presented has been criticised for being inefficient by many researchers as in (Gupta and Dantsiou 2013); these criticisms have signaled a new way of thinking towards a dramatic change in setting up the regulations to meet the requirements of $21^{\text {st }}$ century. These changes need to be done in line with the continuous changes in building design and operations processes which are becoming more ICT (information communication technology) oriented. (Rezgui and Medjdoub 2007) argued that in the face of such trends, design regulations, legislation and building standards, need to urgently comply with these conceptual challenges.

Despite the fact that achieving such conversions is limited by enormous amount of barriers, having regulatory- based IT infrastructure would have significant benefits for the long term of construction (Alavi and Leidner 1999). Some of these barriers are associated with the format of the current compliance requirements representation. Hence, an urgent transformation into logical expressions in a digital format is needed to replace the current textual representation of fragmented sets of information for compliance requirements. The transformation must be conditional to comply with automated extraction of information from regulations while preserving the same context in meeting compliance requirements. The main benefits of achieving such developments within the context of sustainable construction is the potential of applying 
verifiable smart compliance measurement procedures in assessing compliance with sustainable design requirements and achieving optimised design solutions.

In general, the way compliance with regulations is checked by comparing design features against compliance requirements based on the available data and information. Then, a specific approach is used to evaluate the performance according to the nature of information and assessment criteria as follow:

a) Data provided by building users such as operation status the number of occupants using the building, b) Data obtained through the application of simple procedures and calculations based on existing data such as the calculations of volumes, areas, and enumerations, c) Data obtained by using external applications such as numerical values of water and energy consumptions, and d) information provided from external sources and GIS regarding external conditions such as weather and site conditions.

Although there are many tools that could massively facilitate the process through direct integration and smart intelligence, nevertheless, this integration has yet to be achieved.

\section{Framework Development}

The author has identified three major phases in order to achieve automated compliance checking of building performance. The initial phase comprise converting the textual complex format of regulatory into an explicit logical expressions which could support the automation. The second phase includes integrating external applications and building performance simulation tools with compliance checking tools. While in the final phase, having the regulatory requirements embedded into the compliance checking environment. By developing a framework based on these three phases, the process of compliance checking could become more efficient and transparent requires less efforts and investments. The phases of the framework developments are illustrated in Figure 1.

Each phase has some challenges to limit the development of such integrated solutions. For example; in phase, compliance requirements in regulations and standards are described in textual documents that require human interpretation and processing. Therefore, they are not ready to be directly automated. While in line with phase 2 , building performance simulation tools are criticised for their limited interoperability with the requirements of sustainable design specified by sustainability regulations. These twow issues limits the achievement of the final phase of developing the integrated process of automated sustainability compliance checking. It can be summarisd that most of the challenges are associated with information format and information exchange. Nevertheless, the current evolution of Building information modelling technologies and data sharing regime has potentially intensified developing innovative solutions to streamline sustainability compliance checking. 


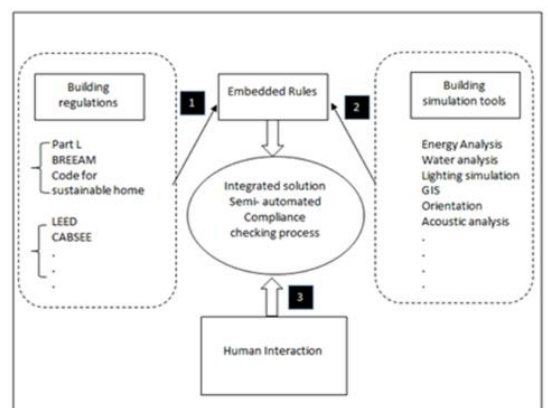

Figure 1. Integrated system for compliance checking

\subsection{Converting Textual Documents into Rules Using RASE}

To develop the system, regulatory statements need to be described using logical decision spreadsheet. To do that, regulatory requirements were analysed and then re- written in a form of series of decision statements. Each of these statements has been placed in a cell within the decision spreadsheet.

One of the challenges was that regulatory statements are written in technical/legal language. They are designed for processing by professionals with experience in the domain and not ready for computer processing. Hence, additional stage was needed for separating the compliance requirements and their applicability to be further reordered into an applicable logical structure (Eastman et al., 2009b). For this purpose, RASE (Requirements, Applications, selection, and exemption) has been utilized in a process called "Marking Up". This process allows adding extra semantic information to the regulation.

Every single decision from compliance requirements assessment criteria has been re-written using RASE through the marked-up. The process involved identifying every 'objects', its 'properties' and 'requirements' for compliance as specified in the regulations. Once this process has been completed, a summary of all the required information to be extracted from the BIM model has been identified.

The software tool has been used to import the original textual statements from the standard document and regualtions and to convert them to XML 'Extensible Markup Language' format. This is done by applying encoding format and applying a set of XML syntax to re-structures of the original sentence. This stage was followed by adding the four RASE operators; selection, application, exemption and requirements. Figure 2 demonstrates an example of regulation text that has been marked up with RASE using Require 1 tool AEC3 Ltd. 


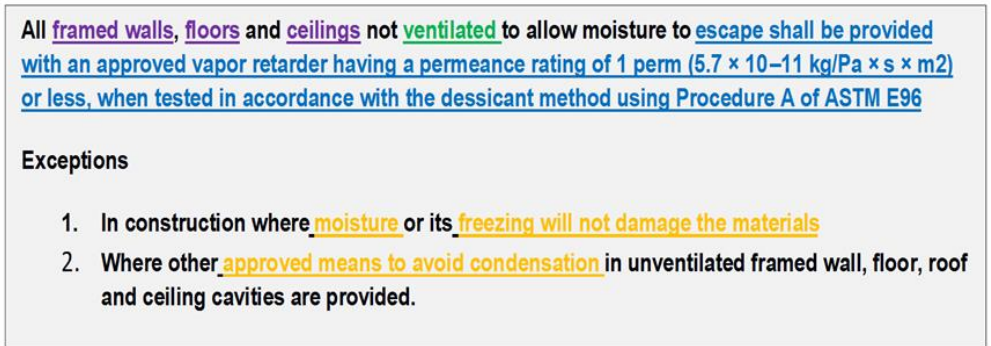

Figure 2. RASE Application using Require 1 tool AEC3 Ltd.

"Requirement: Represents the criteria that are required to be true for a specific decision. It allows the specification of the decision to be made. The requirement statements often start with obligation terms, such as shall, must and so on. A requirement or definition is highlighted in blue", as illustrated in Figure 2.

"Application: Restricts the scope of the decision. The applies statement is highlighted in green in Figure 2. The check applies to the filtered set of items, which are identified separately as an apply tag, for example, the apply tag may indicate that a decision applies to "external" doors only, or only to "Naturally Ventilated" rooms."

"Selection: The select statement is highlighted in purple in the example in Figure 2. Each select statement serves to expand the scope of the decision. Often, a check contains a list of the selection of items to which it relates. There is a dictionary of phrases to define all of the terms used to describe the alternative items. A key feature is that each select statement increases the number of relevant items that are considered, for example, "walls", "floors" and "ceilings"."

"Exception: Specifies the cases to which the check does not apply. An exception is highlighted in orange on the previous example, illustrated in Figure 2. The exception tag also filters the number of items within the scope of the decision." (Kasim, 2015)

\subsection{Rules Processing (Generation and Execution)}

To execute the requirements for sustainability compliance checking, an open-source rule engine has been utilized namely the 'DROOLS rule engine' (Drools, 2013).

An interim stage was required to convert the spreadsheet including the meta data into a format understandable by the rule engine. Therefore DRL (DROOLS Rule Language) (Community, 2013) has been utilized to enable DROOLS rule engine to process the decision spreadsheets and the additional RASE meta-data that has been added to each individual cells within the generated decision spreadsheets.

The conversion from the spreadsheet to DRL is done by using a rule compiler which applies a series of logical formulas, the compiler works according to the decision spreadsheets and the RASE tags. The outcome of this process is a generated DRL ready for processing by DROOLS into an executable code where each individual cell in the decision spreadsheet is treated as a single rule. The process of rule execution is done in two steps: the first step is to determine if the rule is in scope, while the second step shows if the rule has been passed or failed. Figure 3 shows the logical formula 
which was used to process the rules. In figure 3, 'S1 and S2' represent the "Select" RASE Tags, 'E1,E2' represent "Exception" tags, 'A1,A2' represent the "Applies" tags and 'R1,R2' represent the "Requirement" tags.

For a rule to be applicable, it needs at least one selection, all applicability criteria and non of the exceptions must be met. to determine whether the rule has passed or failed, they are examined against meeting the requirements "R1" and "R2".

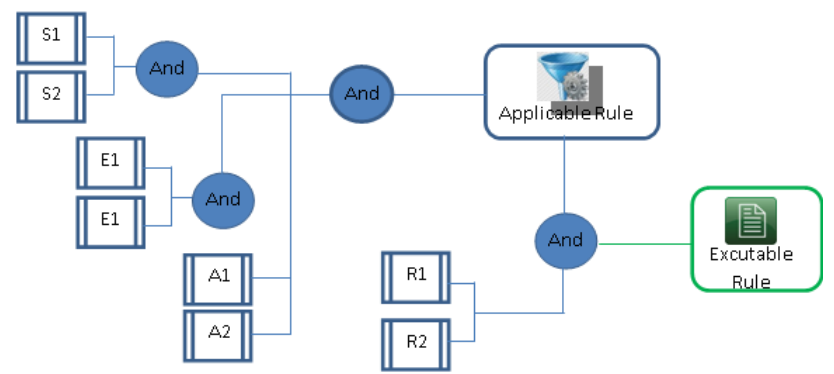

Figure 3. 3.2 Rules processing (Generation and Execution)

\subsection{Mapping Regulatory Requirements to IFC Data Model}

The main aim of using the rule engine is to examine the regulatory compliance of the BIM model. IFC data model has been used for this purpose as the standard data exchange format within Building information modeling environment. However, when IFC data model has been explores to examine the compatibility of data representation with the developed sets of rules, it has been determined that all the main building objects that were previously addressed for compliance are included in the IFC data model. Nevertheless, not all the pre-defined properties of these objects were necessarily fulfilling the requirements for compliance checking; it has been determined that there are still a plethora of characteristics and descriptive attributes to be added to the IFC data model to make it compatible with the compliance checking requirements. The availability of a comprehensive data model is important in order to establish a domain-compliant IFC that is ready for the undertaking automated compliance check. It can be concluded at this stage that the rules engine is only capable for capturing the explicit data requirement directly from the IFC file. These limitations have motivated the author to seek alternative reasoning-based methods to extract more compliance requirements including the implicit requirements for compliance checking. A suggestion for using engineering ontologies has been considered for the aim of gathering the fragmented pieces of axioms from the IFC, in order to build domain ontology; It is not in the scope of this paper to discuss the compliance checking domain ontology, but such development can potentially facilitate extracting a wider range of information from an IFC model. 


\section{Implementation and Results Validation}

Compliance checking system has been implemented in a real case scenario to examine its validity and efficiency. For this purpose, a previously generated BIM model of the design of a new development has been utilized. The case study design model has been provided by Skanska UK Ltd, where the development has been designed to achieve a BREEAM 'excellent' rating.

Figure 4 shows a screenshot of system implementation, in this figure, there is a window of user interaction and additional information requirements that need to be added before running the compliance check. Once added, the system scans the provided BIM model, and in the logical structured process, the system checks the model against compliance requirements (the decision tree is shown in the figure) and finally, the results are reported in a form of credit for compliance with each BREEAM criteria.

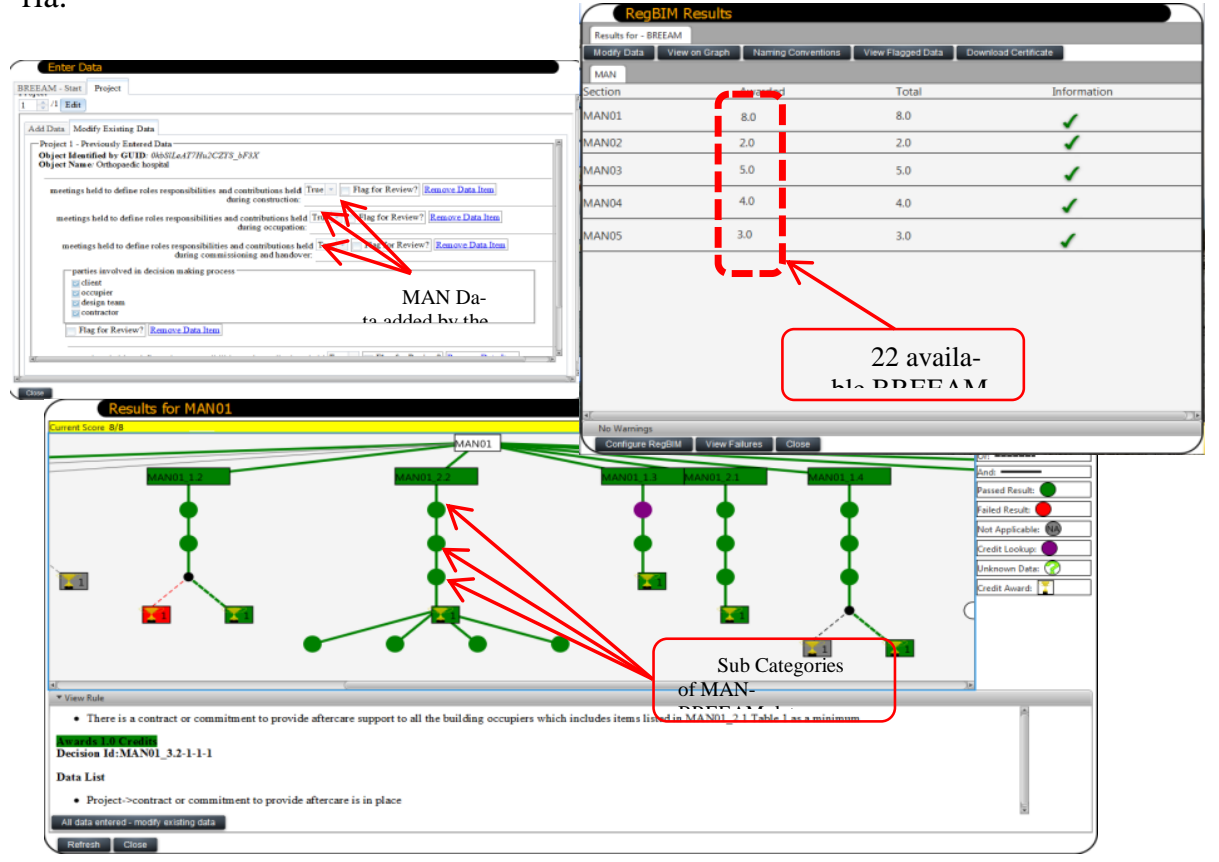

Figure 4 System implementation results

\section{Conclusion}

The developed automated compliance checking process proof to have some limitations. Mainly, because the standard data format IFC lacks representations of all objects attributes needed for compliance checking. As a result, additional data is needed to enrich the current data model and to make it compatible with compliance requirements. When applying the process on a real case study for validation purpose. The 
process shows its validity and reliability and correct results were obtained as verified by a comparison with the traditional BRREAM assessment method.

The key feature of the developed approach is its ability to collect together the compliance information and use it directly as enrichment to the existing BIM model (IFC file). To this end, the developed system shows significant merits in terms of its ability to exploit a considerable amount of knowledge present in a BIM model, but interacting with assessors is still fundamental to close the loop of compliance checking as shown in figure 5. The quantitative representation analysis of compliance checking processes reveals that around half of the compliance requirements need to be addressed by the user and hence human interaction with the system is still required to add the missing domains of data to the IFC. Much of the required data is related to checks on supporting documentation i.e. contracts, and other documentations which are not within the scope of the current IFC.

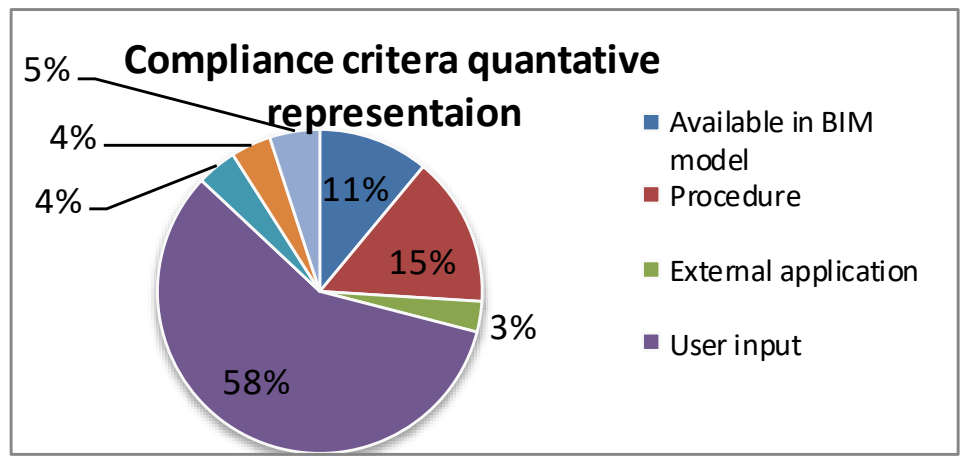

Figure 5. Quantitative representation of compliance checking process

Nevertheless, even in these cases the system facilitates the compliance analysis by providing the user with the list of data that is needed for every decision. This enables the users to be able to visualise the effects of entered data on the final results.

The goal of user engagement is to provide additional pieces of information that can be helpful to proceed with running the compliance checking application automatically. To facilitate the user engagement, a user interface has been developed with a userfriendly interface. And to ensure that the information is consistent terminology and compatible with the rule engine requirements, additional features has been added to the user interface to constrain the data input process

Since the process still requires user engagement, the process is still not fullyautomated. The next stage of the development will involve integrating the current outcome with building simulation tools to enrich the functionality of the semiautomated process. Although automating compliance checking is very difficult to achieve, but this development could open future opportunities for more coherent development to promote efficient compliance checking throughout buildings' life cycle. 


\section{References}

1. AZHAR, S., BROWN, J. \& FAROOQUI, R. 2009. BIM-based sustainability analysis: An evaluation of building performance analysis software. In: Proceedings of the 45th ASC Annual Conference, 2009.

2. BENTLEY. 2016. AECOsim [Online]. 2016 COPYRIGHT BENTLEY SYSTEMS, INCORPORATED. [Accessed October 2016].

3. BISWAS, T. \& TSUNG-HSIEN WANG, R. K. 2008. Integrating sustainable building rating systems with building information models.

4. COUNSELL, J. 2012. Beyond Level 2 BIM, Web Portals and Collaboration Tools. In: 2012 16th International Conference on Information Visualisation, 2012. IEEE, 510-515.

5. CRAWLEY, D. B., LAWRIE, L. K., WINKELMANN, F. C., BUHL, W. F., HUANG, Y. J., PEDERSEN, C. O., STRAND, R. K., LIESEN, R. J., FISHER, D. E. \& WITTE, M. J. 2001. EnergyPlus: creating a new-generation building energy simulation program. Energy and Buildings, 33, 319-331.

6. EASTMAN, C., LEE, J.-M., JEONG, Y.-S. \& LEE, J.-K. 2009. Automatic rule-based checking of building designs. Automation in Construction, 18, 1011-1033.

7. EVERETT, R., BOYLE, G., PEAKE, S. \& RAMAGE, J. 2012. Energy Systems and Sustainability: Power for a Sustainable Future, Oxford Univerity Press.

8. HJELSETH, E. \& NISBET, N. Year. Capturing normative constraints by use of the semantic mark-up (RASE) methodology. In: CIB W78 2011 28th International ConferenceApplications of IT in the AEC Industry, 2011.

9. JAFFE, A. B., NEWELL, R. G. \& STAVINS, R. N. 2005. A tale of two market failures: Technology and environmental policy. Ecological Economics, 54, 164-174.

10.JUNG, Y. \& JOO, M. 2011. Building information modelling (BIM) framework for practical implementation. Automation in Construction, 20, 126-133.

11.Kasim, T. (2015). BIM-Based Smart Compliance Checking to Enhance Environmental Sustainability. PhD. Cardiff University.

12.KHEMLANI, L. 2002. Solibri Model Checker. CADENCE-AUSTIN-, 32-34.

13.KIBERT, C. J. 2008. Sustainable construction: green building design and delivery, Wiley.

14.LEE, N. \& GEORGE, C. 2013. Environmental assessment in developing and transitional countries: principles, methods and practice, Wiley.

15.SALAMA, D. \& EL-GOHARY, N. 2011. Semantic modeling for automated compliance checking. Journal of Computing in Civil Engineering, 641-648.

16.SINGH, R. K., MURTY, H., GUPTA, S. \& DIKSHIT, A. 2012. An overview of sustainability assessment methodologies. Ecological Indicators, 15, 281-299.

17.SINGH, V., GU, N. \& WANG, X. 2011. A theoretical framework of a BIM-based multidisciplinary collaboration platform. Automation in Construction, 20, 134-144.

18.T KASIM, H. J. L., Y REZGUI, T BEACH 2013. Automated Sustainability Compliance Checking Process. EG-ICE International Workshop on Intelligent Computing in Engineering Vienna, Austria.

19.TRUSTY, W. B. 2000. Introducing an assessment tool classification system. Advanced Building Newsletter, 25. 
644 T. Kasim et al.

20.YANG, Q. \& XU, X. 2004. Design knowledge modeling and software implementation for building code compliance checking. Building and Environment, 39, 689-698. 